\title{
Hair cortisol and cortisone measurements for the diagnosis of overt and mild Cushing's syndrome
}

\author{
Julie Brossaud ${ }^{1,2,{ }^{*}}$, Léa Charret ${ }^{3, *}$, Delia De Angeli ${ }^{4,5}$, Magalie Haissaguerre ${ }^{3}$, Amandine Ferriere ${ }^{3}$, Marie Puerto ${ }^{3}$, \\ Blandine Gatta-Cherifi ${ }^{3}$, Jean-Benoît Corcuff ${ }^{1,2}$ and Antoine Tabarin ${ }^{3}$ \\ ${ }^{1}$ Department of Nuclear Medicine, University Hospital of Bordeaux, Bordeaux, France, ${ }^{2}$ Nutrition et Neurobiologie \\ Intégrée, University of Bordeaux, Bordeaux, France, ${ }^{3}$ Department of Endocrinology, Diabetes and Nutrition, CHU of \\ Bordeaux and University of Bordeaux, France, ${ }^{4}$ Department of Radiology, IRCCS Policlinico San Matteo Foundation, \\ Pavia, Italy, and ${ }^{5}$ Department of Clinical-Surgical, Diagnostic and Pediatric Sciences, University of Pavia, Pavia, Italy \\ Correspondence \\ should be addressed \\ to A Tabarin \\ Email \\ antoine.tabarin@chu- \\ bordeaux.fr
}

\begin{abstract}
Objective: Hair cortisol (HF) and cortisone (HE) measurements reflect tissular exposure to cortisol over months and are increased in overt Cushing's syndrome (CS). No data is available in mild CS. We compared the diagnostic performance of $\mathrm{HF}$ and $\mathrm{HE}$ between patients with overt or mild CS.

Design: Single centre retrospective study.

Methods: HF\&HE were measured by LC-MS/MS in 48 consecutive adult females with Cushing's disease (CD), ectopic ACTH syndrome, secreting adenomas and carcinomas, and adrenal incidentalomas. All had impaired dexamethasone suppression tests. Overt CS ( $n=25)$ was diagnosed in front of specific symptoms, a mean UFC (>1.5 ULN) and increased midnight serum cortisol or salivary cortisol. Mild CS $(n=23)$ was diagnosed in patients lacking specific symptoms and displaying at least one additional biological abnormality including mildly increased UFC ( $\leq 1.5$ ULN), increased midnight serum cortisol or salivary cortisol and suppressed plasma ACTH in patients with adrenal tumours. In this study, 84 healthy subjects and obese patients served as controls.

Results: HF and HE showed roughly similar performance in overt CS (92 and 100\% sensitivity, 91 and 99\% specificity, respectively). HF and HE were lower in mild CS but higher than in controls $(P<0.01)$. HE was correlated with midnight serum cortisol $(P<0.02)$ and volume of adrenal incidentalomas $(P<0.04)$ but not with UFC. HF and HE had $59 \%$ and $68 \%$ sensitivity, and 79 and $94 \%$ specificity, respectively, for the diagnosis of mild CS. Contrary to UFC, both HF and HE were in the range of overt CS in 11/23 patients with mild CS. Patients with mild CS and increased HE required more antihypertensive treatments and showed worser lipid profiles than patients with normal HE. Conclusions: HF and HE measurement performed better in overt than in mild CS but is a useful adjunct to diagnose mild CS and to identify adrenocortical incidentalomas responsible for excessive cortisol exposure.
\end{abstract}

\section{Introduction}

Numerous biochemical investigations are available for diagnosis of Cushing's syndrome (CS), including UFC (urinary free cortisol) measurements, serum cortisol concentration after DST (dexamethasone suppression (c) 2021 European Society of Endocrinology Printed in Great Britain test), late-night salivary cortisol (LNSC) or midnight serum cortisol (MSC) assays (1). One major limitation of these tools is that they only measure point cortisol concentrations or short-term cortisol exposure. 
The inherent variability in cortisol secretion during CS is a major issue that justifies the recommendations to perform at least 2 UFC or LNSC tests for its diagnosis $(2,3$, 4). To circumvent this drawback, measurement of cortisol in hair has been proposed. Cortisol is incorporated into the growing hair cells by passive diffusion from blood capillaries, and with the hair having a growth rate of approximately $1 \mathrm{~cm} / \mathrm{month}$, hair is a suitable matrix for the estimation of mid- to long-term tissular exposure to circulating cortisol. Three studies have reported on the diagnostic accuracy of cortisol measurement in a single hair sample $(5,6,7)$ and its usefulness in patients with intermittent/cyclical CS $(5,6,8)$.

The $11 \beta$ hydroxysteroid dehydrogenase type 2 enzyme (11 $\beta$-HSD type 2 ) is expressed in eccrine sweat glands of the skin, resulting in local generation of cortisone from cortisol in hair (9). Whether measurement of hair cortisone (HE) may be more useful than measurement of hair cortisol (HF) has been addressed recently in a single study which suggested that the diagnostic performance of HE measurement is superior to that of HF (7).

Mild CS (also incorrectly termed 'subclinical CS') is characterised by the lack of specific features of CS and a mild hypercortisolism resulting in diagnostic complexity $(10,11)$. Mild CS is associated with various pathologic situations, the most frequent being adrenal incidentalomas $(10,12)$. These tumours may exhibit impaired cortisol suppression following the $1 \mathrm{mg}$ DST, a finding consistent with cortisol secretory autonomy (12) but that frequently contrasts with normal UFC and LNSC levels $(10,11,12,13,14)$, a finding that raises the question of whether some of these tumours induce definitive hypercortisolism $(12,13,15,16,17)$. Earlystage recurrence of Cushing's disease (CD) is another difficult diagnostic situation characterised by mild and highly fluctuating cortisol excess. In addition, it has been shown increased UFC is often a late event during recurrence of $\mathrm{CD}(18,19)$. Last, true de novo mild $\mathrm{CD}$ may be responsible for a minimal excess of cortisol production resulting in normal UFC $(11,20,21)$. To date, no data concerning $\mathrm{HF}$ and $\mathrm{HE}$ measurement in mild CS is available. We hypothesised that the ability of HF and HE measurement to assess the long-term exposure to cortisol may help to diagnose cortisol excess in this situation and compared the diagnostic performance of HF and HE by liquid chromatography coupled with mass spectrometry (LC-MS/MS) between patients with overt CS and mild CS.

\section{Methods}

\section{Participants}

Consecutive patients who were referred to the Endocrinology Department of the University hospital of Bordeaux for suspicion of CS and investigation of adrenal incidentalomas were asked to give a scalp-hair sample for glucocorticoids analysis. All patients gave informed consent before participation in the study and biochemical data were collected under conditions of regular clinical care, with local ethics committee of Bordeaux approval for the use of those data. Medical records were reviewed retrospectively. Only females were included in the study and patients who used topical or systemic corticosteroids were excluded.

Forty-eight female patients were included and classified as having overt CS or mild CS. All had a serum cortisol $>50 \mathrm{nmol} / \mathrm{L}$ after the $1 \mathrm{mg}$ DST. Overt CS was diagnosed in the presence of specific symptoms of cortisol excess after examination by an experienced endocrinologist and various abnormal biochemical tests, including a mean of 2-5 UFC $>1.5$ the upper limit of normal range (ULN) and increased MSC $(\geq 180 \mathrm{nmol} / \mathrm{L})$ or increased LNSC above our reference range. Mild CS was diagnosed in the absence of specific clinical symptoms and at least one of the following endocrine alterations: mildly increased UFC (mean of $2-5$ UFC $\leq 1.5$ ULN), plasma ACTH concentration $\leq 2.2 \mathrm{pmol} / \mathrm{L}$ in patients with adrenocortical tumours, increased MSC or increased LNSC.

The control population consisted of 84 females: 26 obese and/or diabetic patients, 4 patients referred for suspicion of CS and 54 healthy controls. None of these patients suffered from alcoholism, depression or were receiving topical or systemic corticosteroids. All patients had cortisol concentrations $<50 \mathrm{nmol} / \mathrm{L}$ following the $1 \mathrm{mg}$ DST or had normal LNSC.

\section{Hair collection}

In all participants, a lock of hair as thick as a pencil and measuring approximately $3 \mathrm{~cm}$ in length was cut from the posterior vertex as close to the scalp as possible. Hair samples were taped on a sheet of paper and the proximal side of the hairs was indicated. The hair samples were stored in a dry envelope at room temperature until analysis.

\section{Assays}

Serum cortisol was assayed using an automated analyser (Architect, Abbott). ACTH serum concentrations were 
assayed by IRMA (ACTH RIA, BRAHMS, Germany) according to the manufacturer's instructions.

For saliva assays, a liquefying agent (Sputasol, Thermo Fisher Scientific) was added to $400 \mu \mathrm{L}$ of saliva samples which were then incubated $30 \mathrm{mn}$ at $37^{\circ} \mathrm{C}$. Then, either saliva or urine samples were prepared for cortisol measurement using automated solid-phase extraction (Oasis HLB, Waters Ltd, Elstree, Hertfordshire, UK). Both salivary and urinary extracts were processed by LC-MS/ MS, with a Prominence Liquid Chromatography system (Shimadzu, Nakagyo, Japan) and a 5500Qtrap detector (Sciex, DC, USA) for saliva samples and Alliance 2695 and Quattro micro Waters systems for urine samples. Cortisol concentration was evaluated using the peak area ratio of the transitions of cortisol and deuterated cortisol from an added internal standard.

Milled hair samples (Precellys®24 instrument, Montigny-le-Bretonneux, France) were incubated for 2 $\mathrm{h}$ in a dithiothreitol solution $(0.77 \mathrm{mg} / \mathrm{mL} \mathrm{NaOH} 0.1 \mathrm{~N})$. The supernatant was extracted by liquid-liquid extraction with dichloromethane. Assays were performed by LCMS/MS (Prominence Liquid Chromatography system, Shimadzu and 5500 Qtrap detector, Sciex). Cortisol and cortisone concentrations were evaluated using the peak area ratio of the transitions of cortisol or cortisone and deuterated cortisol from an added internal standard.

Serum cortisol assay Interassay coefficients of variation $(\mathrm{CV})$ were $<5 \%$ at 97,394 and $800 \mathrm{nmol} / \mathrm{L}$. The limit of quantification is $11 \mathrm{nmol} / \mathrm{L}$. Plasma ACTH assay Interassay CVs are $<5 \%$ at 7.7 and $73 \mathrm{pmol} / \mathrm{L}$. The limit of quantification is $1.16 \mathrm{pmol} / \mathrm{L}$. LNSC LC-MSMS assay interassay CVs were $<10 \%$ at $0.9,2.9$ and $9.2 \mathrm{nmol} / \mathrm{L}$. The limits of quantification is 0.28 . UFC LC-MSMS assays interassay CVs were $<10 \%$ at 9.5 and $132 \mu \mathrm{g} / \mathrm{L}$, respectively. The limits of quantification was $2.5 \mu \mathrm{g} / \mathrm{L}$. HF and HE assays' interassay CVs were $<20 \%$ at 22 and $40 \mathrm{pg} /$ $\mathrm{mg}$ and the limits of quantification was 6.0 and $2.0 \mathrm{pg} /$ $\mathrm{mg}$, respectively.

\section{Statistical analysis}

ACTH and cortisol concentrations below the detection limit of the assay were set to the lowest detection value for calculation purposes. The volume of adrenal nodules was estimated from dedicated CT scans using the formula: $4 / 3 \times \Pi \times r^{3}$. For the purpose of calculation, the sum of volumes was used in those patients with multinodular disease. Daily drug dosage (DDD) calculations were based on tables of equivalent antihypertensive power for the various antihypertensive drugs that patients were taking (22). The daily defined dose (DDD) tables were provided by the hypertension unit of Pompidou European Hospital (Paris, France). Statistical analyses were performed using GraphPad Prism version 8.4.2 (GraphPad Software) and MedCalc version 19.4.1 (MedCalc Software Ltd, Ostend, Belgium). All quantitative variables are expressed as median and interquartile range (IQR). Chi-square, Spearman correlation, Passing-Bablok regression, Mann-Whitney, Kruskal-Wallis, ANOVA test after Logtransformation of data when necessary followed by post hoc tests were used as appropriate. Cut-off values used for the calculation of sensitivities and specificities were determined by receiver operating characteristic (ROC) curves. All outcomes were considered statistically significant where $P$ values were $<0.05$.

\section{Results}

The characteristics of control subjects and patients are summarised in Table 1 and Fig. 1.

Table 1 Characteristics of control subjects and patients. Data are shown as median (IQR).

\begin{tabular}{lcc}
\hline & & Controls \\
\cline { 1 - 1 } Age, y & & 84 \\
BMI, kg/m² & & $24.4(28.2-56.5)^{\mathrm{a}}$ \\
DST, nmol/L & $27(19-28)^{\mathrm{c}}$ \\
UFC, ULN & \\
MSC, nmol/L & \\
HF, pg/mg & $8.7(6.7-11.8)^{\mathrm{e}}$ \\
HE, pg/mg & $13.9(11.0-16.6)^{\mathrm{g}}$ \\
Ratio HF/HE & $0.7(0.5-0.9)$ \\
\hline
\end{tabular}

\begin{tabular}{c}
\hline Overt CS \\
\hline 25 \\
$53.0(35.5-58.5)$ \\
$29.8(26.6-33.3)$ \\
$367(302-526)^{\mathrm{d}}$ \\
$3.9(2.5-7.1)$ \\
$475.0(392.5-565.0)$ \\
$58.8(25.3-78.0)^{\mathrm{f}}$ \\
$68.2(39.0-117.6)^{\mathrm{h}}$ \\
$0.6(0.5-0.9)$
\end{tabular}

\begin{tabular}{c}
\hline Mild CS \\
\hline 23 \\
$55.0(44.0-68.0)$ \\
$29.4(26.2-34.3)$ \\
$165(94-269)$ \\
$0.5(0.2-0.8)$ \\
$194.3(146.5-293.5)$ \\
$14.5(6.2-29.7)$ \\
$27.8(12.3-41.7)$ \\
$0.6(0.3-0.9)$ \\
\hline
\end{tabular}

P values

$<0.02$
$<0.01$
$<0.01$
$<0.01$
$<0.01$
$<0.01$
$<0.01$
0.6

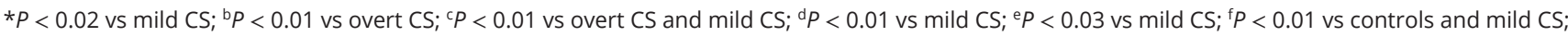
$\mathrm{g} P<0.01$ vs overt CS and mild CS; $\mathrm{h} P<0.01$ vs mild CS.

CS, Cushing's syndrome; DST, serum cortisol concentration following the 1 mg overnight dexamethasone test; HE, hair cortisone; HF, hair cortisol; MSC, midnight serum cortisol; UFC, 24-h urinary free cortisol; ULN, upper limit of normal. 

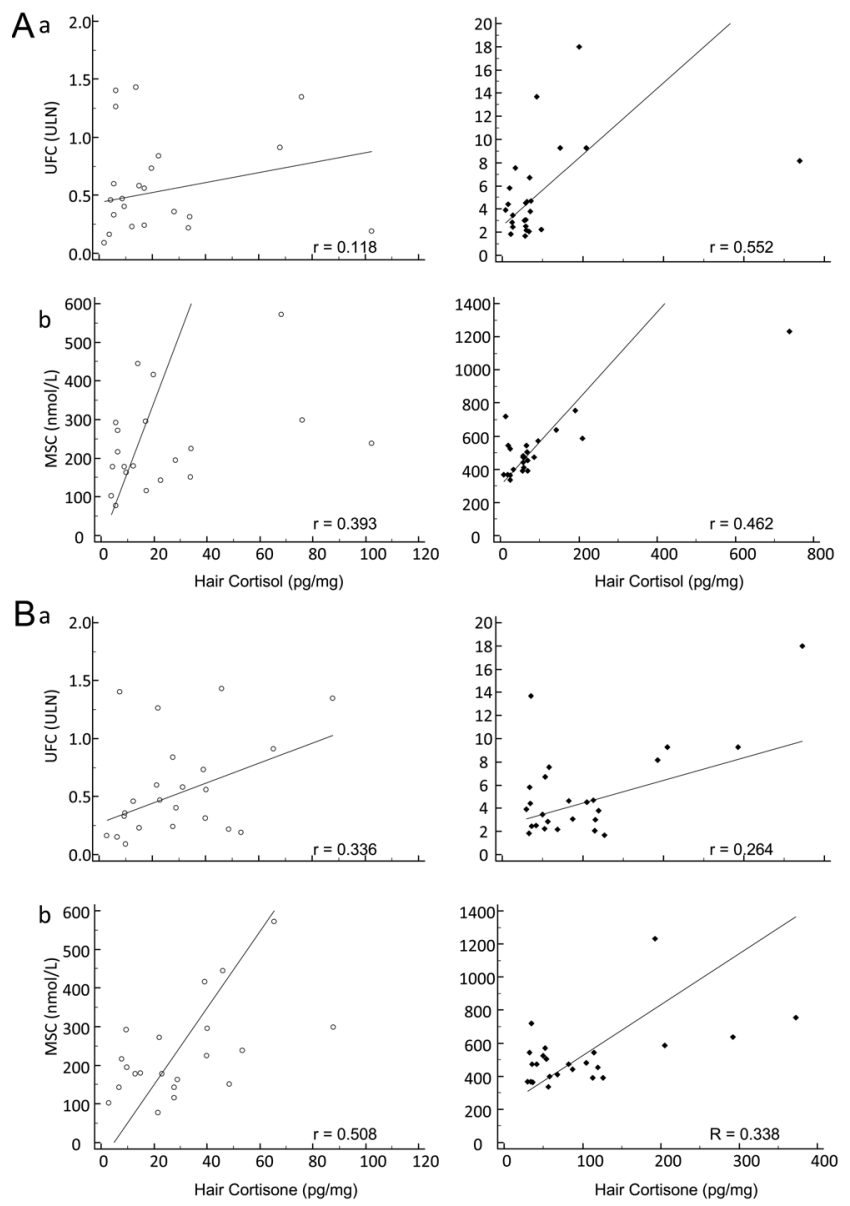

\section{Figure 1}

Distribution of hair cortisol (A) and hair cortisone (B) according to (A) urinary free cortisol (UFC) and midnight serum cortisol (MSC) (B); mild Cushing's syndrome: left panels, overt Cushing's syndrome: right panels. Coefficients of correlation are presented on each plot.

\section{Control population}

HE concentrations were higher than HF concentrations $(P<0.01)$. We found no difference in $\mathrm{HF}$ and $\mathrm{HE}$ concentrations between obese and lean/overweight subjects: $\mathrm{HF}=10.0 \mathrm{pg} / \mathrm{mg}(5.9-19.7)$ vs $8.6 \mathrm{pg} / \mathrm{mg}$ (7.011.3), respectively; $P=0.4 ; \mathrm{HE}=15.1 \mathrm{pg} / \mathrm{mg}(7.7-19.3) \mathrm{vs}$ $13.9 \mathrm{pg} / \mathrm{mg}$ (11.1-16.2), respectively; $P=0.7$ ) nor between older (age $\geq 60$ years) and younger (age $<60$ years) controls: $\mathrm{HF}=8.8 \mathrm{pg} / \mathrm{mg}(5.9-11.3)$ vs $8.9 \mathrm{pg} / \mathrm{mg}$ (6.912.6), respectively; $P=0.6 ; \mathrm{HE}=13.9 \mathrm{pg} / \mathrm{mg}(8.7-18.8) \mathrm{vs}$ $13.9 \mathrm{pg} / \mathrm{mg}$ (11.0-16.4), respectively; $P=0.8$ ). In addition, no correlation was found between $\mathrm{HF}$ and HE levels and BMI nor age (HF: $r=-0.03, P=0.8$ and $r=-0.15, P=0.2$; respectively; HE: $r=0.02$, and $r=0.01, P=0.9$ for both; respectively). Consequently, the values of $\mathrm{HF}$ and $\mathrm{HE}$
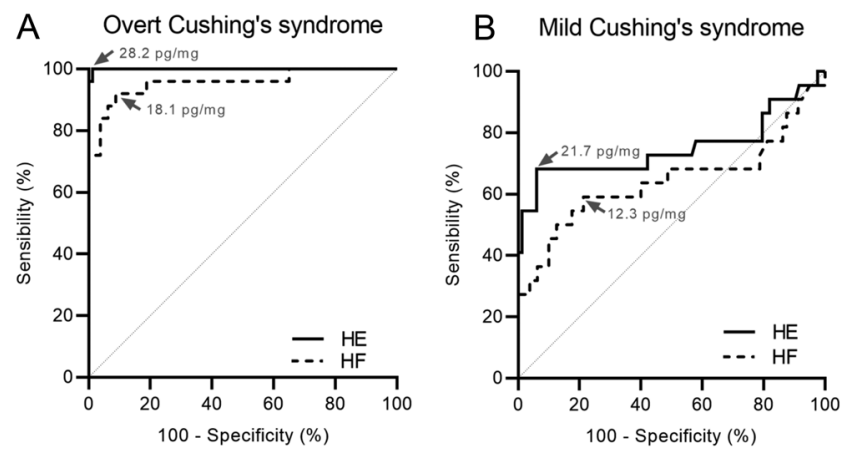

Figure 2

ROC curves for overt (A) and mild (B) Cushing's syndrome. $\mathrm{HE}$, hair cortisone; HF, hair cortisol. The values quoted in the figures correspond to the specific HE and HF diagnostic thresholds with best compromise between sensitivity and specificity.

from the different control groups were pooled as a single cohort.

\section{Overt Cushing's syndrome}

According to our criteria, 25 patients had overt CS: 17 cases of de novo $\mathrm{CD}$ and 1 recurrence after surgical remission, 2 with ectopic ACTH syndrome, 5 with cortisolsecreting tumours (2 adenomas, 3 carcinomas). CD was confirmed by histopathological analysis or post-operative corticotropic insufficiency in 15 cases, and the results of bilateral inferior petrosal sinus sampling in 2 cases. Patients with overt CS had higher BMI than controls but were of similar age (Table 1).

HE concentrations were higher than HF concentrations $(P<0.02)$. HF and HE were associated $(r=0.74, P<0.01)$. HF was also correlated with UFC $(r=0.46, P<0.03)$ and MSC $(r=0.55, P<0.01)$, as opposed to HE $(r=0.26, P=0.2$ and $r=0.34, P=0.11$; respectively) (Fig. 1 ). There was no statistically significant linear association between the HF/ HE ratio and UFC $(r=0.39, P=0.09)$. However, the half of the patients with the highest HF values had higher HF/ $\mathrm{HE}$ ratio than the half of the patients with the lowest $\mathrm{HF}$ values $=0.81(0.58-1.71)$ vs $0.54(0.44-0.64)$, respectively; $P<0.01$.

$\mathrm{HF}$ and $\mathrm{HE}$ concentrations were higher in overt CS than in controls $(P<0.01)$ while $\mathrm{HF} / \mathrm{HE}$ ratio were similar (Table 1). There was no significant difference between the area under the curve (AUC) of ROC curves for $\mathrm{HF}$ and HE (0.96 (95\% CI : 0.90-1.00) vs 0.99 (0.99-1.00), respectively; $P=0.11$ ) (Fig. $2 \mathrm{~A}$ ). With an optimal cut-off of $18.1 \mathrm{pg} / \mathrm{mg}$, HF measurement displayed a sensitivity of 

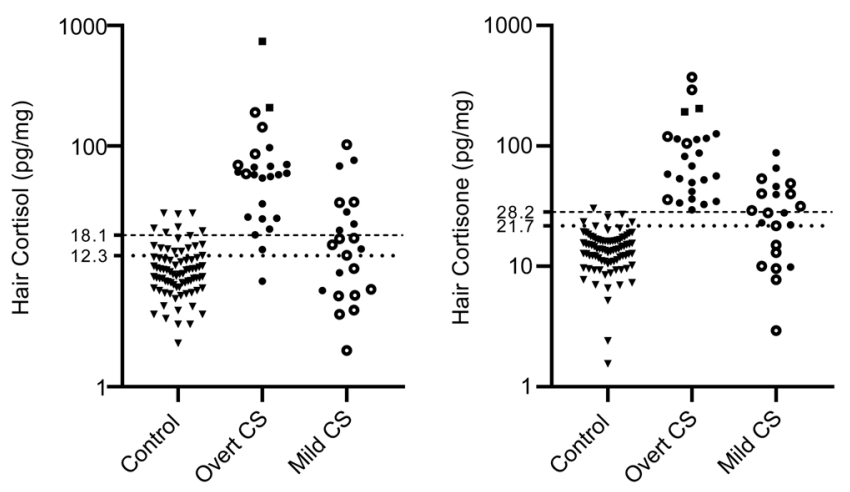

\section{Figure 3}

Hair cortisol and cortisone concentrations (logarithmic scale) in control subjects, patients with overt and mild Cushing's syndrome (CS). Values of patients with Cushing's disease are shown as closed circles, those of patients with adrenal disease are shown as open circles and those of patients with ectopic ACTH syndrome are shown as closed squares. The dotted horizontal lines represent the diagnostic thresholds issued from ROC curves analysis in overt CS (large dashes) and mild CS (small dashes).

$92.0 \%$ and a specificity of $91.3 \%$. With an optimal cutoff of $28.2 \mathrm{pg} / \mathrm{mg}$, HE displayed a sensitivity of $100.0 \%$, and a specificity of $98.8 \%$ (Fig. 3). Two of the 25 patients had normal HF concentrations (7.5 and 13.8) associated with increased HE concentrations (29.5 and 34.8, respectively). As expected, patients with ectopic ACTH syndrome and intense hypercortisolism had the highest HF concentrations (Fig. 3).

The sensitivity of UFC to diagnose overt CS (e.g. mean UFC $>1.5$ ULN), based on 49 analyses performed in the 25 patients during the same period, was $93.9 \%$. Three patients had intermittent hypercortisolism with one UFC $<1.5$ ULN. HE and HF measurements covering this period were increased in these three patients.

\section{Mild Cushing's syndrome}

Twenty-three patients had mild CS: 8 patients had CD (5 de novo disease and 3 early-stage recurrence after surgical remission) and 15 had adrenal disease: 8 patients with unilateral adrenocortical incidentalomas, 6 with bilateral macronodular adrenal hyperplasia (BMAH) and 1 with primary pigmented nodular adrenocortical disease. Definitive diagnosis of CD or its recurrence was based on histopathological analysis and/or corticotropic insufficiency after re-operation.
HE concentrations were higher than HF concentrations $(P<0.01)$. HE was positively correlated with HF $(r=0.78$, $P<0.01)$ and MSC $(r=0.51, P<0.02)$ but not with UFC $(r=0.34, P=0.12)$. HF was not associated with MSC nor UFC ( $r=0.39, P=0.09$ and $r=0.12, P=0.60$, respectively) (Fig. 1).

HF and HE concentrations were higher in patients with mild CS compared to controls but lower than in patients with overt CS (Table 1). HF/HE ratio were similar between these groups (Table 1). Following ROC analysis of data from controls and mild CS patients the AUC of HF and HE did not differ significantly (HF $0.64(0.48-0.80)$ vs HE 0.75 (0.59-0.90), $P=0.3$ ) (Fig. 2). With an optimal cutoff of $12.3 \mathrm{pg} / \mathrm{mg}$, HF measurement displayed a sensitivity of $59.1 \%$ and a specificity of $78.8 \%$. With an optimal cutoff of $21.7 \mathrm{pg} / \mathrm{mg}$, HE displayed sensitivity of $68.2 \%$ and a specificity of $94.0 \%$ (Fig. 3). Three patients had normal HF concentrations $(6.3,8.9$ and $9.6 \mathrm{pg} / \mathrm{mg})$ in the presence of increased HE concentrations (22.1, 23.0, $29.1 \mathrm{pg} / \mathrm{mg}$, respectively). Conversely, one patient had a normal HE concentration at $9.9 \mathrm{pg} / \mathrm{mg}$ while $\mathrm{HF}$ was increased at $28.3 \mathrm{pg} / \mathrm{mg}$. During the period covered by hair analysis, the sensitivity of UFC based on 40 samples was $27.5 \%$

\section{Comparison of biological investigations between patients with mild Cushing's disease and cortisol secretory autonomy}

Compared to patients with adrenal disease, patients with CD had similar cortisol levels following the $1 \mathrm{mg}$ DST (155.0 (94.0-260.0) vs $170.5 \mathrm{nmol} / \mathrm{L}$ (97.8-308.8), respectively; $P=0.6)$, increased UFC $(0.31(0.19-0.56)$ vs 0.88 ULN (0.54-1.33), respectively; $P<0.01)$ and increased MSC (178.0 (129.5-231.0) vs $284.3 \mathrm{nmol} / \mathrm{L}$ (182.-436.8), respectively; $P<0.02$ ). Cortisol levels after DST were $>140$ $\mathrm{nmol} / \mathrm{L}$ in 10/15 patients and between 70 and $140 \mathrm{nmol} / \mathrm{L}$ in the $5 / 15$ patients with adrenal disease. Fourteen of these 15 patients had 08:00 h plasma ACTH $<2.2 \mathrm{pmol} / \mathrm{L}$.

The concentrations of HF and HE were not significantly different between patients with $\mathrm{CD}$ and adrenal disease: HF 21.2 (10.1-58.2) vs $11.0 \mathrm{pg} / \mathrm{mg}$ (5.3-21.3), respectively; $P=0.15$ and HE 33.6 (22.3-60.7) vs $24.8 \mathrm{pg} / \mathrm{mg}$ (9.9-40.1), respectively; $P=0.24$. Seven of eight patients with $C D$ and $8 / 15$ patients with adrenal disease had increased HE. Interestingly, $5 / 8$ patients with $\mathrm{CD}$ and $6 / 15$ patients with adrenal disease had increased values of HE that were in the range of patients with overt CS. During the period covered by hair analysis, the sensitivity of UFC $37.5 \%$ in patients with $\mathrm{CD}$ and $12.5 \%$ in patients with adrenal tumours. 
Table 2 Metabolic status of patients with mild CS and normal $(<28.2)$ or increased $(\geq 28.2)$ concentrations of Hair Cortisone (HE).

\begin{tabular}{l}
\hline \\
\hline BMI, kg/m² \\
Hypertension, $n$ (\%) \\
Antihypertensive medication, DDD \\
SBP, mmHg \\
DBP, mmHg \\
Diabetes mellitus, $n$ (\%) \\
FBG, g/L \\
HbA1c, \% \\
Triglycerides, g/L \\
LDL cholesterol, g/L \\
HDL cholesterol, g/L
\end{tabular}

\begin{tabular}{cl}
\hline & HE $(\mathrm{pg} / \mathrm{m}$ \\
\hline$<28.2(n=11)$ \\
\hline $26.2(20.9-33.6)$ \\
$8(72.7)$ \\
$1.0(0.0-2.0)$ \\
$141.0(116.0-145.0)$ \\
$73.0(67.0-90.0)$ \\
$1(9.1)$ \\
$0.86(0.79-1.01)$ \\
$5.9(5.2-6.3)$ \\
$1.01(0.61-1.52)$ \\
$1.23(1.07-1.53)$ \\
$0.57(0.53-0.72)$ \\
\hline
\end{tabular}

HE $(\mathrm{pg} / \mathrm{mg})$

$\begin{aligned} \geq & 28.2(n=8) \\ 30.8 & (29.0-35.3) \\ 7 & (87.5) \\ 3.0 & (1.8-4.0) \\ 131.5 & (125.5-146.5) \\ 79.5 & (68.5-88.3) \\ 0 & (0.0) \\ 0.94 & (0.87-1.04) \\ 5.8 & (5.6-6.3) \\ 2.11 & (1.28-2.42) \\ 1.35 & (1.18-1.77) \\ 0.47 & (0.41-0.62)\end{aligned}$

0.1

0.05

0.8

0.8

0.4

0.98

$<0.01$

0.4

$P=0.06$

Quantitative data are shown as median (IQR).

DDD, daily defined dose of antihypertensive treatment; DSP, diastolic blood pressure; FBG, fasting blood glucose; SBP, systolic blood pressure.

The estimated volume of adrenal nodules was 12.2 (8.2-27.1) vs $55.3 \mathrm{~cm}^{3}(16.9-162.5)$ in patients with unilateral $v s$ bilateral disease, respectively $(P<0.02)$. There was no significant association between the estimated volume and serum cortisol concentrations following the $1 \mathrm{mg}$ DST ( $r=0.12 ; P=0.67)$. Cortisol concentrations following the DST were similar between patients with unilateral and bilateral adrenal lesions (174.5 nmol/L (83.6-268.5) vs $150.5 \mathrm{nmol} / \mathrm{L}$ (94.5-258.6), respectively; $P>0.99)$. HF and HE were associated with the volume of nodules: $r=0.63$ and 0.59 , respectively; $P<0.04$ for both. HE but not HF, was increased in bilateral adrenal disease compared to unilateral disease: $\mathrm{HE}=30.3(23.2-46.6)$ vs $11.3 \mathrm{pg} / \mathrm{mg}$ (6.5-21.3), respectively; $P<0.05$ and $\mathrm{HF}=16.1$ $(6.6-34.0)$ vs $6.1 \mathrm{pg} / \mathrm{mg}(4.2-13.5)$, respectively; $P=0.18$.

\section{Clinical features in patients with mild CS and increased $\mathrm{HE}$}

We compared several cortisol-induced cardiovascular risk factors between patients with mild CS and increased or normal HE (Table 2). To avoid the confounding effects of sequelae arising from a previous history of CD, only patients with de novo MCD and with adrenal disease were considered. Despite similar blood pressure values, patients with increased HE had an increased daily drug dosage of antihypertensive drugs, increased plasma triglyceride concentrations and a trend towards lower HDL concentrations. The median DDD of antihypertensive drugs decreased from 1.8 to 0.6 in 12 of these patients who underwent surgery (pituitary surgery in 5, resection of unilateral adenoma in 5 and unilateral adrenalectomy for BMAH in 2 patients).

\section{Discussion}

Overall, our study confirms the excellent performance of hair cortisol analysis for the diagnosis of overt CS and provides complementary insights into the respective diagnostic value of HF and HE measured by LC-MS/MS. We found that the performance of HF\&HE measurement was lower in mild CS than in overt CS. However, it was clearly better than that of UFC for the diagnosis of mild de novo $\mathrm{CD}$ and $\mathrm{CD}$ in early-stage recurrence. Our results further demonstrate the heterogeneity in cortisol secretion within adrenal incidentalomas associated with cortisol secretory autonomy (CSA). In this situation, HF\&HE identified patients with excessive tissular exposure to cortisol and, possibly, increased cortisol-related comorbidities.

Measurement of $\mathrm{HF}$ and $\mathrm{HE}$ was associated with sensitivities of 92 and 100\% and specificities of 91 and 99\% for diagnosis of overt CS. The number of patients in our study was limited but this performance compares well with the $81-93 \%$ sensitivity and $88-98 \%$ specificity reported in the three published studies measuring hair cortisol using different techniques (immunoassay or LC-MS/MS) in 14-70 patients with overt CS $(5,6$, 7). Interestingly, the sensitivity of a single HF\&HE measurement in our cohort was roughly comparable to that of several UFC determinations performed in the same period. Cortisone in scalp hair results either from diffusion of serum cortisone or conversion of cortisol by local 11 $\beta$-HSD2 (9). As described for salivary cortisol and cortisone $(1,23)$, the typically higher HE concentrations than HF reflects the activity of $11 \beta$-HSD type 2 in the scalp that amplify the cortisol signal. One recently published study found a slightly better performance of $\mathrm{HE}$ measurement over HF, using LC-MS/MS, when the results 
of two independent cohorts of 19 and 70 patients with CS were pooled (7). We also found a slightly better diagnostic accuracy for HE measurement over HF, though this did not reach statistical significance, a finding that may have been due to the limited size of our patient cohort. Whether HE provides a substantial diagnostic improvement over HF measurement is therefore a matter for future research, as well as comparison of measurements of HF using immunoassays with HF and HE measurement using LCMS/MS. Interestingly, we found that patients with the highest HF concentrations displayed higher HF/HE ratio as compared to patients with lowest HF values. This may reflect the limited ability of the scalp 11ß-HSD type 2 to convert HF to HE at relatively high HF levels as described for the kidney in patients with Cushing's syndrome (24).

Hair sampling has a number of advantages: it is non-invasive and does not require specific timing, hair samples can be stored at room temperature and be sent by mail. Above all, HF and HE measurements reflect longterm glucocorticoid exposure and are not influenced by acute stressors. As illustrated in a few patients in our series, this unique feature could make it possible to substitute a single hair sample for several urine or saliva samples that are necessary in those patients with variable hormonogenesis $(3,2,5,6,8,11)$. However, $\mathrm{HF}$ and HE measurement suffers from several limitations such as the cumbersome and time-consuming preparation and extraction of hair samples. This particular matrix sample and multiple steps of the assay (sample preparation, sample weighing, standard preparation, extraction, chromatography, detection by LCMS) often leads to higher interassay variability with coefficients of variations ranging between 15 and $20 \%(25,26)$. It has also been shown that frequent hair washing (27) and dye hair may lead to hair cortisol washout. Last, cortisol incorporation in hair shaft, hair growth rate and matrix composition depend on the ethnic group and age (28). All these issues contribute to intra and inter-individual variability resulting in decreased diagnostic performance. In our opinion and in the context of clinical suspicion of CS, HF and HE measurements should therefore be reserved for use in difficult diagnostic cases such as cyclic Cushing's syndrome and performed in expert laboratories taking into account the factors of variability.

Mild CS represents a complex diagnostic situation that requires the use of specific biochemical investigations, and eventually the use of different thresholds than those used for diagnosis of overt CS $(10,11,12,14,20)$. Indeed, the diagnosis of $\mathrm{CD}$ of mild intensity requires repeated measurements of UFC (which may be impractical), and
LNSC in addition to DST (11). An increase in UFC is also a late event during post-operative recurrence of $\mathrm{CD}$ and diagnosing early-stage recurrence, a phase that is characterised by intermittent cortisol overproduction, also requires multiples LNSC measurements with specific thresholds to be captured $(1,2,11,18,19,30)$. Although conducted in a small series, our results suggest that HF and HE may be of diagnostic utility since of the $7 / 8$ patients who displayed increased values, 5 of these were in the range of overt $\mathrm{CD}$.

Depending on the series and criteria used, mild CS has been described in 5 to $50 \%$ of patients with adrenal incidentalomas $(10,12)$. The ESE has proposed a definition of this condition as ACS, a terminology that reflects the pathophysiology of the disease, for example, cortisol secretion disconnected from control by the HPA axis, as reflected by impaired cortisol suppression following the 1mg DST (12). However, whether ACS results in definitive hypercortisolism is debatable since UFC and LNSC are normal in the majority of patients $(10,13,31)$. These discrepancies may result from a variety of causes including false positives of the DST $(4,12,13,32)$. Additionally, one common limitation of LNSC and UFC measurements is that they evaluate point cortisol production in fluids where cortisol circulates or is excreted and may ignore intermittent cortisol overproduction resulting in tissular accumulation. Using the unique characteristic of the hair matrix to assess the long-term tissular exposure to cortisol, we found that roughly half of the patients with ACS had increased HF\&HE that were in the range of patients with overt $\mathrm{CD}$, in contrast to normal or borderline UFC. Consistent with this, HE was associated with the volume of adrenal lesions, an estimation of the secretory mass, and was greater in bilateral compared to unilateral incidentalomas. A study using six daily saliva samples collected from awakening to night, showed that patients with ACS had increased AUC for salivary cortisol due to increased morning levels, while LNSC was identical to that of non-functioning incidentalomas (33). Aside from unrecognised intermittent cortisol over-production, this secretory profile may also explain increased $\mathrm{HF}$ and $\mathrm{HE}$ over a period of months contrasting with normal LNSC and normal UFC due to the limited spillover of cortisol into urine. Measurement of HF and HE may therefore be substituted for multiple repeated biochemical investigations to characterise the secretory status in ACS (12). Similarly to our findings in overt CS, the slightly better performance of HE measurement as compared to HF for the diagnosis of mild CS did not reach statistical 
significance, a result that could be due to the limited size of our cohort of patients and needs to be addressed in larger independent studies.

Increased long-term cortisol exposure within normal range levels, evaluated by $\mathrm{HE}$ in large populations, is associated with cardiovascular risk factors (34). Interestingly, increased HE in our patients with mild CS was associated with potent cortisol-induced comorbidities such as the intensity of hypertension and dyslipidemia. Furthermore, a reduction in the DDD of antihypertensive drugs was observed after cure of mild CS. These findings are unsurprising in view of the frequency of hypertension in $\mathrm{CD}$ and $\mathrm{ACS}$, the frequent improvement of hypertension after excision of adrenal incidentalomas with ACS (12, 35 ) and the clinical benefit of treatment of mild CD (19). Assessing whether increased HF and HE might serve as a predictor of clinical improvement following surgery of adrenal incidentalomas with ACS could be an important aim of future studies, given the poor predictive value of the usual biochemical investigations $(13,35,36)$.

Our study does, however, suffer from various limitations including those inherent to a retrospective study and the limited size of our cohort of mild CS patients. Our results should therefore be considered preliminary and require confirmatory studies with larger cohorts. Only female patients were included in our study and our results cannot be extrapolated to male patients. Gender-specific thresholds should be determined since HF concentrations are increased in males compared to females $(28,37,38)$. Our study included mainly healthy subjects and obese patients without disturbance of the HPA axis function as the control group. In the context of ACS, complementary studies of patients with nonsecreting adrenal incidentalomas will be necessary. Although consecutive patients with overt CS have been studied, a referral bias may have positively influenced the diagnostic accuracy of HF and HE compared to a more general real-life practice that would be enriched with patients with an unconfirmed suspicion of CS (39). Additionally, chronic stress and depression may increase HF levels (38). Establishing thresholds after the inclusion of patients with these pathologies will be important to enable the differential diagnosis between mild CD and 'pseudo-Cushing's syndrome' $(29,40)$. Contrary to our findings, some (though not all) authors have reported a positive correlation between HF levels and age or massive obesity $(41,42)$. Therefore, establishing appropriate normative ranges of concentrations in various populations, as has been published for LNSC and salivary cortisone, will be important to assess the diagnostic value of HF and HE measurements in mild CS (43). Last, the relatively important inter-assay variability of $\mathrm{HF}$ and HE measurements discussed previously may represent a limitation for an accurate measurement of mildest tissular overexposure to cortisol.

In conclusion, our study confirms the excellent performance of HF\&HE assay for the diagnosis of overt CD. Given its convenience and high sensitivity, we believe that the overnight DST remains the first-line test of choice for the screening of overt CS, mild CS and ACS $(1,4,11,12)$. However, due to limitations in specificity, complementary investigations are needed to ensure definitive diagnosis ( 1 , $4,12,13)$. HF and HE may also be definitively increased in patients with mild $\mathrm{CD}$ and may therefore be a useful adjunct for this diagnosis and a substitute for repeated biochemical evaluations, including repeated LNSC measurement $(11,18,21)$. Amongst patients with ACS in whom LNSC if often noncontributive $(14,31,33)$, HF and HE measurement is able to identify individuals with tissular over-exposure to cortisol. Whether increased HF\&HE in these patients is an indicator of clinical severity, favouring adrenal surgery, remains to be studied. Recent steroid profiling analysis has also suggested that measurement of other glucosteroids (such as corticosterone) may identify patients with ACS at risk of their cardiovascular status worsening with time (44). Measurement of the cumulative deposition of these steroids in scalp hair may also be an area for future research.

\section{Declaration of interest}

The authors declare that there is no conflict of interest that could be perceived as prejudicing the impartiality of the research reported.

\section{Funding}

This research did not receive any specific grant from any funding agency in the public, commercial or not-for-profit sector.

\section{References}

1 Galm BP, Qiao N, Klibanski A, Biller BMK \& Tritos NA. Accuracy of laboratory tests for the diagnosis of Cushing syndrome. Journal of Clinical Endocrinology and Metabolism 2020105 2081-2094. (https:// doi.org/10.1210/clinem/dgaa105)

2 Sandouk Z, Johnston P, Bunch D, Wang S, Bena J, Hamrahian A \& Kennedy L. Variability of late-night salivary cortisol in Cushing disease: a prospective study. Journal of Clinical Endocrinology and Metabolism 2018103 983-990. (https://doi.org/10.1210/jc.201702020)

3 Petersenn S, Newell-Price J, Findling JW, Gu F, Maldonado M, Sen K, Salgado LR, Colao A, Biller BMK \& Pasireotide B2305 Study Group. High variability in baseline urinary free cortisol values in patients with Cushing's disease. Clinical Endocrinology 201480 261-269. (https://doi.org/10.1111/cen.12259) 
4 Nieman LK, Biller BMK, Findling JW, Newell-Price J, Savage MO, Stewart PM \& Montori VM. The diagnosis of Cushing's syndrome: an Endocrine Society clinical practice guideline. Journal of Clinical Endocrinology and Metabolism 200893 1526-1540. (https://doi. org/10.1210/jc.2008-0125)

5 Wester VL, Reincke M, Koper JW, Akker ELT van den, Manenschijn L, Berr CM, Fazel J, Rijke YB de, Feelders RA \& Rossum EFC van. Scalp hair cortisol for diagnosis of Cushing's syndrome. European Journal of Endocrinology 2017176 695-703. (https://doi.org/10.1530/EJE-160873)

6 Manenschijn L, Koper JW, van den Akker EL, de Heide LJ, Geerdink EA, de Jong FH, Feelders RA \& van Rossum EF. A novel tool in the diagnosis and follow-up of (cyclic) Cushing's syndrome: measurement of long-term cortisol in scalp hair. Journal of Clinical Endocrinology and Metabolism 201297 E1836-E1843. (https://doi. org/10.1210/jc.2012-1852)

7 Savas M, Wester VL, Rijke YB de, Rubinstein G, Zopp S, Dorst K, Berg SAA van den, Beuschlein F, Feelders RA, Reincke M, et al. Hair glucocorticoids as a biomarker for endogenous Cushing's syndrome: validation in two independent cohorts. Neuroendocrinology 2019109 171-178. (https://doi.org/10.1159/000498886)

8 Thomson S, Koren G, Fraser LA, Rieder M, Friedman TC \& Van Uum SHM. Hair analysis provides a historical record of cortisol levels in Cushing's syndrome. Experimental and Clinical Endocrinology and Diabetes 2010118 133-138. (https://doi. org/10.1055/s-0029-1220771)

9 Smith RE, Maguire JA, Stein-Oakley AN, Sasano H, Takahashi K, Fukushima K \& Krozowski ZS. Localization of 11 beta-hydroxysteroid dehydrogenase type II in human epithelial tissues. Journal of Clinical Endocrinology and Metabolism 199681 3244-3248. (https://doi. org/10.1210/jcem.81.9.8784076)

10 Chiodini I. Clinical review: diagnosis and treatment of subclinical hypercortisolism. Journal of Clinical Endocrinology and Metabolism 201196 1223-1236. (https://doi.org/10.1210/jc.2010-2722)

11 Kidambi S, Raff H \& Findling JW. Limitations of nocturnal salivary cortisol and urine free cortisol in the diagnosis of mild Cushing's syndrome. European Journal of Endocrinology 2007 157 725-731. (https://doi.org/10.1530/EJE-07-0424)

12 Fassnacht M, Arlt W, Bancos I, Dralle H, Newell-Price J, Sahdev A, Tabarin A, Terzolo M, Tsagarakis S \& Dekkers OM. Management of adrenal incidentalomas: European society of endocrinology clinical practice guideline in collaboration with the European network for the study of adrenal tumors. European Journal of Endocrinology 2016 175 G1-G34. (https://doi.org/10.1530/EJE-16-0467)

13 Cambos S \& Tabarin A. Management of adrenal incidentalomas: working through uncertainty. Best Practice and Research: Clinical Endocrinology and Metabolism 202034 101427. (https://doi. org/10.1016/j.beem.2020.101427)

14 Nunes ML, Vattaut S, Corcuff JB, Rault A, Loiseau H, Gatta B, Valli N, Letenneur L \& Tabarin A. Late-night salivary cortisol for diagnosis of overt and subclinical Cushing's syndrome in hospitalized and ambulatory patients. Journal of Clinical Endocrinology and Metabolism 200994 456-462. (https://doi. org/10.1210/jc.2008-1542)

15 Giorgi RB, Correa MV, Costa-Barbosa FA \& Kater CE. Cyclic subclinical hypercortisolism: a previously unidentified hypersecretory form of adrenal incidentalomas. Journal of the Endocrine Society 20193 678-686. (https://doi.org/10.1210/js.201800385)

16 Terzolo M, Stigliano A, Chiodini I, Loli P, Furlani L, Arnaldi G, Reimondo G, Pia A, Toscano V, Zini M, et al. AME position statement on adrenal incidentaloma. European Journal of Endocrinology 2011164 851-870. (https://doi.org/10.1530/EJE-10-1147)

17 Stewart PM. Is subclinical Cushing's syndrome an entity or a statistical fallout from diagnostic testing? Consensus surrounding the diagnosis is required before optimal treatment can be defined. Journal of Clinical Endocrinology and Metabolism 201095 2618-2620. (https:// doi.org/10.1210/jc.2010-0633)

18 Danet-Lamasou M, Asselineau J, Perez P, Vivot A, Nunes ML, Loiseau H, San-Galli F, Cherifi-Gatta B, Corcuff JB \& Tabarin A. Accuracy of repeated measurements of late-night salivary cortisol to screen for early-stage recurrence of Cushing's disease following pituitary surgery. Clinical Endocrinology 201582 260-266. (https:// doi.org/10.1111/cen.12534)

19 Carroll TB, Javorsky BR \& Findling JW. Postsurgical recurrent Cushing disease: clinical benefit of early intervention in patients WITH normal urinary free cortisol. Endocrine Practice 201622 1216-1223. (https://doi.org/10.4158/EP161380.OR)

20 Tabarin A \& Perez P. Pros and cons of screening for occult Cushing syndrome. Nature Reviews. Endocrinology 20117 445-455. (https:// doi.org/10.1038/nrendo.2011.51)

21 Elias PCL, Martinez EZ, Barone BFC, Mermejo LM, Castro M \& Moreira AC. Late-night salivary cortisol has a better performance than urinary free cortisol in the diagnosis of Cushing's syndrome. Journal of Clinical Endocrinology and Metabolism 201499 2045-2051. (https://doi.org/10.1210/jc.2013-4262)

22 Maxwell M, Heaney D, Howie JG \& Noble S. General practice fundholding: observations on prescribing patterns and costs using the defined daily dose method. BMJ 1993307 1190-1194. (https:// doi.org/10.1136/bmj.307.6913.1190)

23 Raff H \& Phillips JM. Bedtime salivary cortisol and cortisone by LC-MS/MS in healthy adult subjects: evaluation of sampling time. Journal of the Endocrine Society 20193 1631-1640. (https://doi. org/10.1210/js.2019-00186)

24 Stewart PM, Walker BR, Holder G, O'Halloran D \& Shackleton CH. 11 Beta-hydroxysteroid dehydrogenase activity in Cushing's syndrome: explaining the mineralocorticoid excess state of the ectopic adrenocorticotropin syndrome. Journal of Clinical Endocrinology and Metabolism 199580 3617-3620. (https://doi.org/10.1210/ jcem.80.12.8530609)

25 Noppe G, Rijke YB de, Dorst K, Akker ELT van den \& Rossum EFC. LC-MS/MS-based method for long-term steroid profiling in human scalp hair. Clinical Endocrinology 201583 162-166. (https://doi. org/10.1111/cen.12781)

26 Gaudl A, Kratzsch J, Bae YJ, Kiess W, Thiery J \& Ceglarek U. Liquid chromatography quadrupole linear ion trap mass spectrometry for quantitative steroid hormone analysis in plasma, urine, saliva and hair. Journal of Chromatography A 20161464 64-71. (https://doi. org/10.1016/j.chroma.2016.07.087)

27 Hamel AF, Meyer JS, Henchey E, Dettmer AM, Suomi SJ \& Novak MA. Effects of shampoo and water washing on hair cortisol concentrations. Clinica Chimica Acta: International Journal of Clinical Chemistry 2011412 382-385. (https://doi.org/10.1016/j. cca.2010.10.019)

28 Staufenbiel SM, Penninx BWJH, Rijke YB de, Akker ELT van den \& Rossum EFC van. Determinants of hair cortisol and hair cortisone concentrations in adults. Psychoneuroendocrinology 201560 182-194. (https://doi.org/10.1016/j.psyneuen.2015.06.011)

29 Papanicolaou DA, Yanovski JA, Cutler GB, Chrousos GP \& Nieman LK. A single midnight serum cortisol measurement distinguishes Cushing's syndrome from pseudo-Cushing states. Journal of Clinical Endocrinology and Metabolism 199883 1163-1167. (https://doi.org/10.1210/jcem.83.4.4733)

30 Bou Khalil R, Baudry C, Guignat L, Carrasco C, Guibourdenche J, Gaillard S, Bertagna X \& Bertherat J. Sequential hormonal changes in 21 patients with recurrent Cushing's disease after successful pituitary surgery. European Journal of Endocrinology 2011165 729-737. (https:// doi.org/10.1530/EJE-11-0424)

31 Masserini B, Morelli V, Bergamaschi S, Ermetici F, Eller-Vainicher C, Barbieri AM, Maffini MA, Scillitani A, Ambrosi B, Beck-Peccoz P, et al. The limited role of midnight salivary cortisol levels in the diagnosis of subclinical hypercortisolism in patients with adrenal 
incidentaloma. European Journal of Endocrinology 2009160 87-92. (https://doi.org/10.1530/EJE-08-0485)

32 Ueland GÅ, Methlie P, Kellmann R, Bjørgaas M, Åsvold BO, Thorstensen K, Kelp O, Thordarson HB, Mellgren G, Løvås K, et al. Simultaneous assay of cortisol and dexamethasone improved diagnostic accuracy of the dexamethasone suppression test. European Journal of Endocrinology 2017176 705-713. (https://doi.org/10.1530/ EJE-17-0078)

33 Ceccato F, Barbot M, Albiger N, Antonelli G, Zilio M, Todeschini M, Regazzo D, Plebani M, Lacognata C, Iacobone M, et al. Daily salivary cortisol and cortisone rhythm in patients with adrenal incidentaloma. Endocrine 201859 510-519. (https://doi.org/10.1007/ s12020-017-1421-3)

34 Stalder T, Kirschbaum C, Alexander N, Bornstein SR, Gao W, Miller R, Stark S, Bosch JA \& Fischer JE. Cortisol in hair and the metabolic syndrome. Journal of Clinical Endocrinology and Metabolism 201398 2573-2580. (https://doi.org/10.1210/jc.2013-1056)

35 Bancos I, Alahdab F, Crowley RK, Chortis V, Delivanis DA, Erickson D, Natt N, Terzolo M, Arlt W, Young WF, et al. Therapy of endocrine disease: improvement of cardiovascular risk factors after adrenalectomy in patients with adrenal tumors and subclinical Cushing's syndrome: a systematic review and meta-analysis. European Journal of Endocrinology 2016175 R283-R295. (https://doi. org/10.1530/EJE-16-0465)

36 Eller-Vainicher C, Morelli V, Salcuni AS, Battista C, Torlontano M, Coletti F, Iorio L, Cairoli E, Beck-Peccoz P, Arosio M, et al. Accuracy of several parameters of hypothalamic-pituitary-adrenal axis activity in predicting before surgery the metabolic effects of the removal of an adrenal incidentaloma. European Journal of Endocrinology 2010163 925-935. (https://doi.org/10.1530/EJE-10-0602)

37 Abell JG, Stalder T, Ferrie JE, Shipley MJ, Kirschbaum C, Kivimäki M $\&$ Kumari M. Assessing cortisol from hair samples in a large observational cohort: the Whitehall II study. Psychoneuroendocrinology 201673 148-156. (https://doi.org/10.1016/j.psyneuen.2016.07.214)
38 Wester VL \& Rossum EFC van. Clinical applications of cortisol measurements in hair. European Journal of Endocrinology 2015173 M1-M10. (https://doi.org/10.1530/EJE-15-0313)

39 Kannankeril J, Carroll T, Findling JW, Javorsky B, Gunsolus IL, Phillips J \& Raff H. Prospective evaluation of late-night salivary cortisol and cortisone by EIA and LC-MS/MS in suspected Cushing syndrome. Journal of the Endocrine Society 20204 bvaa107. (https:// doi.org/10.1210/jendso/bvaa107)

40 Findling JW \& Raff H. Diagnosis of endocrine disease: differentiation of pathologic/neoplastic hypercortisolism (Cushing's syndrome) from physiologic/non-neoplastic hypercortisolism (formerly known as pseudo-Cushing's syndrome). European Journal of Endocrinology 2017176 R205-R216. (https://doi.org/10.1530/EJE-16-0946)

41 Wester VL, Staufenbiel SM, Veldhorst MAB, Visser JA, Manenschijn L, Koper JW, Klessens-Godfroy FJM, Akker ELT van den \& Rossum EFC van. Long-term cortisol levels measured in scalp hair of obese patients. Obesity 201422 1956-1958. (https://doi.org/10.1002/oby.20795)

42 Chan J, Sauvé B, Tokmakejian S, Koren G \& Van Uum S. Measurement of cortisol and testosterone in hair of obese and non-obese human subjects. Experimental and Clinical Endocrinology and Diabetes 2014122 356-362. (https://doi. org/10.1055/s-0034-1374609)

43 Bäcklund N, Brattsand G, Israelsson M, Ragnarsson O, Burman P, Engström BE, Høybye C, Berinder K, Wahlberg J, Olsson T, et al. Reference intervals of salivary cortisol and cortisone and their diagnostic accuracy in Cushing's syndrome. European Journal of Endocrinology 2020182 569-582. (https://doi.org/10.1530/EJE19-0872)

44 Di Dalmazi G, Fanelli F, Zavatta G, Ricci Bitti S, Mezzullo M, Repaci A, Pelusi C, Gambineri A, Altieri P, Mosconi C, et al. The steroid profile of adrenal incidentalomas: subtyping subjects with high cardiovascular risk. Journal of Clinical Endocrinology and Metabolism 2019104 5519-5528. (https://doi.org/10.1210/jc.201900365)

Received 29 September 2020

Revised version received 4 January 2021

Accepted 15 January 2021 